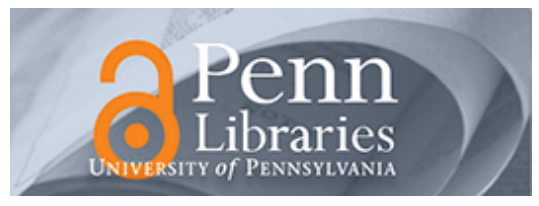

University of Pennsylvania

ScholarlyCommons

Management Papers

Wharton Faculty Research

$11-2004$

\title{
What Makes Negotiators Happy? The Differential Effects of Internal and External Social Comparisons on Negotiator Satisfaction
}

\author{
Nathan Novemsky \\ Maurice E. Schweitzer \\ University of Pennsylvania
}

Follow this and additional works at: https://repository.upenn.edu/mgmt_papers

Part of the Business Administration, Management, and Operations Commons, Business Intelligence Commons, Cognition and Perception Commons, Cognitive Psychology Commons, Experimental Analysis of Behavior Commons, Interpersonal and Small Group Communication Commons, Management Sciences and Quantitative Methods Commons, and the Personality and Social Contexts Commons

\section{Recommended Citation}

Novemsky, N., \& Schweitzer, M. E. (2004). What Makes Negotiators Happy? The Differential Effects of Internal and External Social Comparisons on Negotiator Satisfaction. Organizational Behavior and Human Decision Processes, 95 (2), 186-197. http://dx.doi.org/10.1016/j.obhdp.2004.05.005

This paper is posted at ScholarlyCommons. https://repository.upenn.edu/mgmt_papers/311

For more information, please contact repository@pobox.upenn.edu. 


\title{
What Makes Negotiators Happy? The Differential Effects of Internal and External Social Comparisons on Negotiator Satisfaction
}

\begin{abstract}
This paper examines the role of internal and external social comparisons in negotiator satisfaction. Internal comparisons involve another party to the negotiation (e.g., buyer compared to seller), while external comparisons focus on someone outside of the negotiation (e.g., buyer compared to other buyers). Negotiator satisfaction can influence a range of post-negotiation behavior, but relatively little is known about what makes negotiators more or less satisfied. In many contexts negotiators receive little objective feedback and lack benchmarks against which to judge their outcome. Prior work has modeled negotiator satisfaction as a function of utility maximization, expectancy disconfirmation, and internal social comparisons (social utility). In this paper we identify another particularly important driver of negotiator satisfaction, external social comparisons. Across five studies we demonstrate that external social comparisons affect satisfaction and that the effects of external social comparisons are qualitatively different from those of internal social comparisons. In particular, we find that downward external social comparisons increase satisfaction, while downward internal social comparisons decrease satisfaction. These results inform important prescriptions, and we discuss implications of these results for managing negotiator satisfaction.
\end{abstract}

\section{Keywords}

negotiation, satisfaction, social comparison

\section{Disciplines}

Business Administration, Management, and Operations | Business Intelligence | Cognition and Perception | Cognitive Psychology | Experimental Analysis of Behavior | Interpersonal and Small Group Communication | Management Sciences and Quantitative Methods | Personality and Social Contexts 
What Makes Negotiators Happy?

The Differential Effects of Internal and External Social Comparisons on

Negotiator Satisfaction

\author{
Nathan Novemsky \\ School of Management \\ Yale University \\ New Haven, CT 06520 \\ Phone/Fax: 203-436-4261/432-3003 \\ E-mail: Nathan.novemsky@yale.edu
}

Maurice E. Schweitzer

Wharton School

University of Pennsylvania

Philadelphia, PA 19104

Phone/Fax: 215-898-4776/3664

E-mail: Schweitzer@wharton.upenn.edu 


\title{
What Makes Negotiators Happy? \\ The Differential Effects of Internal and External Social Comparisons on Negotiator Satisfaction
}

\begin{abstract}
This article examines the role of internal and external social comparisons in negotiator satisfaction. Internal comparisons involve another party to the negotiation (e.g. buyer compared to seller), while external comparisons focus on someone outside of the negotiation (e.g. buyer compared to other buyers). Negotiator satisfaction can influence a range of post-negotiation behavior, but relatively little is known about what makes negotiators more or less satisfied. In many contexts negotiators receive little objective feedback and lack benchmarks against which to judge their outcome. Prior work has modeled negotiator satisfaction as a function of utility maximization, expectancy disconfirmation and internal social comparisons (social utility). In this article we identify another particularly important driver of negotiator satisfaction, external social comparisons. Across five studies we demonstrate that external social comparisons affect satisfaction and that the effects of external social comparisons are qualitatively different from those of internal social comparisons. In particular, we find that downward external social comparisons increase satisfaction, while downward internal social comparisons decrease satisfaction. These results inform important prescriptions, and we discuss implications of these results for managing negotiator satisfaction.
\end{abstract}

Key Words: Negotiation, Satisfaction, Social Comparison 
While some goods and services are exchanged in transparent markets at fixed market clearing prices, many other exchanges are characterized by a zone of indeterminacy (Rees, 1993) and involve negotiations. In these latter cases, people may have a poor sense of how good their outcome actually was (Blount, Thomas-Hunt, \& Neale, 1996). Despite this uncertainty, negotiators assess their satisfaction with a negotiated outcome, and these satisfaction judgments have important implications for future behavior. For example, dissatisfied negotiators may be less likely to follow through on an agreement and less likely to negotiate with the same counterpart in the future (Barry \& Oliver, 1996).

In this article we investigate the satisfaction process, and conceptualize negotiator satisfaction as a labile and manipulable construct. While prior work has identified a number of important determinants of negotiator satisfaction, we identify an important omission in this literature. Prior work has identified self-interested utility maximization (e.g., how low was the price I paid for the car), expectancy disconfirmation (e.g., how does the price I paid compare to the amount I expected to pay), and internal social comparisons (or social utility; e.g., how does the surplus I earned from this deal compare to the amount of surplus the seller earned from the deal) as important determinants of negotiator satisfaction. In this article we examine the role of external social comparisons (e.g. how does the price I paid compare to the price others in a similar situation paid) in satisfaction judgments. We demonstrate that external social comparisons significantly influence negotiator satisfaction, and that external social comparisons have independent and qualitatively different effects on satisfaction from internal social comparisons. 


\section{$\underline{\text { Negotiator Satisfaction }}$}

While prior work has found that negotiators tend to be more satisfied when they earn higher outcomes (Gillespie, Brett, \& Weingart, 2000), negotiators often have difficulty evaluating their outcome. In many cases objective measures do not exist, and disputants lack information to guide their evaluation process (Hsee, 1996). Instead, negotiator satisfaction is likely to be heavily influenced by psychological factors.

Prior research has largely focused on two psychological determinants of satisfaction-expectancy disconfirmation and internal social comparisons. Oliver, Balakrishnan and Barry (1994) formalize an expectancy disconfirmation model of negotiator satisfaction. In their model, negotiators develop expectations prior to a negotiation and evaluate their outcome relative to these expectations. Consistent with their model, Oliver et al. (1994) find that the difference between negotiators' expectations and outcomes is significantly correlated with negotiator satisfaction. These results are consistent with Conlon and Ross' (1993) findings in a series of mediation studies. They find that negotiators who set lower expectations are more satisfied with their outcomes. In many cases, however, the link between expectations and satisfaction is likely to be complicated. Negotiators' expectations shift during the negotiation process (Brett, Northcraft, \& Pinkley, 1999), and negotiator expectations themselves can influence outcomes (White \& Neale, 1994).

A second stream of satisfaction research involves internal social comparisons and considers the importance of evaluating one's outcome relative to one's counterpart's outcome. Loewenstein, Thompson and Bazerman (1989) refer to this construct as social utility, and they develop a model to predict satisfaction in a bargaining context. Across 
three experiments they find support for their model that includes terms for the difference between one’s own outcome and one’s counterpart's outcome.

$\underline{\text { Internal versus External Social Comparison }}$

In this work we consider a different type of social comparison, external social comparison. External social comparisons are particularly important in situations that lack objective standards (Festinger, 1954), and consequently, we expect external social comparison judgments to play an important role in negotiator satisfaction.

In contrast to Loewenstein et al.'s (1989) focus on comparisons with others in the same negotiation, we consider the influence of comparisons with others outside of the negotiation. This distinction is important for several reasons. First, internal social comparisons and external social comparisons are conceptually distinct. These two types of comparisons focus attention in different ways, and we expect internal and external social comparisons to influence negotiator satisfaction very differently. Specifically, internal social comparisons focus attention on the part of the bargaining zone that the negotiator did not claim. While this focus alone may lower satisfaction, the tendency for negotiators to assume that they claimed most of the available surplus (Larrick \& Wu, 2003) might enhance the likelihood that an internal comparison will induce disappointment. As a result, we propose that internal social comparison values, even those that inform a negotiator that she captured most of the bargaining zone (i.e. downward comparisons), are likely to lower satisfaction.

The proposition that even downward internal social comparison values may lower satisfaction is consistent with prior work that has found that negotiators tend to be less satisfied when they believe that they could have earned higher outcomes. For example, 
Galinsky, Seiden, Kim and Medvec (2002) find that even when negotiators earned more surplus, they were less satisfied when their counterpart immediately accepted their first offer than when their counterpart did not immediately accept their first offer. In other work, Naquin (2003) finds that negotiators are less satisfied when their negotiation involves a large number of issues than when their negotiation involves a small number of issues, because negotiators are concerned that they will miss opportunities for increasing their surplus—a legitimate concern (Moran \& Ritov, 2002; Pinkley, Griffith, and Northcraft, 1995).

External social comparisons are less clearly related to forgone opportunities than are internal social comparisons. Therefore, we expect upward external social comparisons to decrease satisfaction and downward external social comparisons to increase satisfaction.

Another difference between internal and external comparisons is that unlike external social comparisons, internal social comparisons confound relative performance with fairness. In fact, fairness considerations are an essential part of Loewenstein et al.'s (1989) framework, prompting them to use scenarios with equal surplus outcomes as the baseline case. In our studies we use the absence of comparison information as our control condition to examine the absolute influence of introducing comparison information.

\section{Study 1}

Our first study examines the influence of external social comparison values on negotiator satisfaction. Although prior work has identified a link between internal social comparison cues and satisfaction in scenario studies (Loewenstein et al., 1989), we 
explore a different set of social comparison cues, external rather than internal social comparisons, in a different context, a negotiation exercise.

In our study, participants experienced a number of factors in addition to external social comparison cues that are likely to influence their satisfaction. For example, participants' satisfaction in our experiment may have been influenced by how much participants liked each other, how high or low their expectations were, the sequence of offers and counter-offers, persuasive arguments, and even their own affective states. Taken together, these factors may compete with or even overwhelm the effects of external social comparisons.

Method

A sample of 354 undergraduate and MBA students completed an in-class exercise on the first day of class. Participants read background information regarding the sale of a used truck. Participants were randomly paired and assigned to the role of either buyer or seller. Buyers had private information regarding an alternative truck they could purchase for $\$ 5500$, and sellers had private information regarding an alternative buyer who would be willing to purchase the truck for $\$ 3500$. Participants bargained in pairs until they reached an agreement, decided they could not reach an agreement, or reached the set time limit (of 40 minutes).

After completing the exercise, groups of participants were exposed to an external social comparison manipulation. We randomly assigned groups of approximately 20 dyads to be exposed to either a high or a low external social referent. The experimenter asked one pair in each experimental session to reveal their final price. In the high external 
social referent condition, that pair had reached an agreement of $\$ 5500^{1}$. In the low external social referent condition, the group was exposed to an agreement of $\$ 4500$. Participants were led to believe that the experimenters had forgotten to distribute the post-negotiation survey and had mistakenly started the debriefing. Immediately following this manipulation, and before any further discussion of the exercise, participants completed a survey that contained our primary dependent measures. All participants were asked, "How satisfied are you with your outcome from this negotiation?” and "How satisfied are you with the negotiation process?” Each question was asked with an 11point scale ranging from extremely unsatisfied to extremely satisfied. Then as a manipulation check, they judged how well their outcome compares to outcomes of others in the same role. Buyers were asked how their outcome compares to other buyers’ outcomes and sellers were asked to compare their outcome to other sellers. The 11-point response scale ranged from worst in the class to best in the class.

\section{$\underline{\text { Results }}$}

A total of 316 participants reached an agreement within the allotted time and completed all dependent measures. Final prices ranged from $\$ 3500$ to $\$ 5500$ with a mean of $\$ 4746$ and a standard deviation of $\$ 508$. Outcome and process satisfaction were highly correlated $(\underline{r}=.62$ for buyers, $\underline{\mathrm{p}}<.001 ; \underline{\mathrm{r}}=.64$ for sellers, $\underline{\mathrm{p}}<.001)$ and separate analyses of outcome satisfaction and process satisfaction produced similar patterns of results. In the analyses that follow, we used an overall measure of satisfaction: the sum of outcome and process satisfaction.

\footnotetext{
${ }^{1}$ Since one experimental session did not include a dyad who reached an agreement at \$5500, we used an agreement of $\$ 5250$ in that session.
} 
As depicted in Figure 1, our external social comparison cues significantly influenced social comparison judgments. Buyers exposed to the high external social referent judged that they had performed relatively better than buyers exposed to the low external social referent, $(\mu=5.6$ versus $\mu=4.8, \underline{\mathrm{t}}(151)=3.37, \underline{\mathrm{p}}<.001)$. As expected, this pattern was reversed for sellers. Sellers exposed to the low external social referent thought they had performed relatively better than sellers exposed to the high external social referent, $(\mu=5.9$ versus $\mu=4.9$, $\underline{\mathrm{t}}(145)=3.97, \underline{\mathrm{p}}<.001)$.

More importantly, the external social comparison manipulation influenced participants’ satisfaction (see Figure 2). As expected, buyers in the high external social referent condition were more satisfied than buyers in the low external social referent condition, $(\mu=12.9$ versus $\mu=11.8, \underline{\mathrm{t}}(152)=1.89, \underline{\mathrm{p}}<.05)$, and sellers in the low external social referent condition were more satisfied than sellers in the high external social referent condition, $(\mu=12.9$ versus $\mu=11.8$, $\underline{\mathrm{t}}(145)=1.95, \underline{\mathrm{p}}<.05)$.

\section{$\underline{\text { Discussion }}$}

These results identify a causal link between external social comparison cues and satisfaction. Incidental social comparison cues had a dramatic effect on satisfaction despite all the other information available in the negotiation context. Like car buyers in a dealership, participants in our experiment had a prolonged interaction including discussion, an exchange of offers, and both verbal and non-verbal reactions to each other's offers. All of these cues could have affected their negotiation satisfaction. Even with these competing cues, however, we find that external social comparison values have a substantial effect on satisfaction. In practice, a number of factors are likely to moderate the relationship between external social comparison cues and satisfaction. For example, 
Goethals and Darley (1977) suggest that social comparison effects can be moderated by the relationship between the referent and the perceiver, the relative status of the referent and the perceived competency the referent.

\section{Study 2}

In our second study we examine the influence of external social comparison information relative to other determinants of satisfaction. Unlike Study 1, we do not focus participants' attention on external social comparison cues. Instead, we examine the influence of self-constructed external and internal social comparisons on negotiator satisfaction. Unlike previous experimental studies of social comparison in negotiations, our design enables us to assess the relative contribution of different drivers of satisfaction in a more natural context where attention is not artificially drawn to social comparisons.

To assess the relative influence of different drivers of satisfaction we compare four alternative models of negotiator satisfaction. We derive the first three models from prior research: an objective utility model, a social utility model, and an expectancy disconfirmation model. We develop the fourth model to represent the role of external social comparison judgments in satisfaction.

Method

A total of 188 graduate and undergraduate business students participated in a bargaining exercise on the first day of a negotiation class. They participated in the same bargaining exercise used in Study 1. After participants read their background information, but before they bargained, participants were asked to predict the price they were most likely to agree on with their partner (Oliver, Balakrishnan, and Barry, 1994). Participants then bargained in pairs until they reached an agreement, decided they could 
not reach an agreement, or reached the set time limit (of 40 minutes). After the bargaining session all participants responded to a post-bargaining questionnaire. This questionnaire asked participants to judge their satisfaction with their outcome (from extremely unsatisfied to extremely satisfied), their satisfaction with the bargaining process (using the same satisfaction scale as the one we used in Study 1), and how well they thought their outcome compared to other participants in their same role (from much better than others to much worse than others). They were also asked to estimate their partner's reservation price. Sellers were asked to estimate the highest price their buyer would pay and buyers were asked to estimate the lowest price their seller would accept. $\underline{\text { Results }}$

A total of 156 participants reached an agreement and completed all dependent measures. Final prices ranged from $\$ 3600$ to $\$ 5800$, with a mean of $\$ 4850$ and standard deviation of $\$ 516$. As in Study 1, we summed outcome and process satisfaction $(\underline{r}=.48$ for buyers, $\underline{p}<.001 ; \underline{r}=.62$ for sellers, $\underline{p}<.001$ ) to produce one overall measure of satisfaction.

In this study we focus on the effects of objective outcomes, social utility, expectancy disconfirmation, and external social comparison on satisfaction. Consistent with this approach we develop and compare four alternative models of satisfaction. To help gauge the performance of these models, we introduce a combined model that includes all the factors used in the four models of interest. We describe each of these models in turn.

Objective Utility Model. We derive the first model from classical economics which posits a relationship between the objective measure of price and satisfaction. We 
include a quadratic term in our model to allow for diminishing marginal utility. The objective utility model is represented in Equation 1.

$$
\begin{aligned}
\text { Satisfaction }_{O U}= & \beta_{1}(\text { objective outcome })+\beta_{2}(\text { objective outcome })^{2} \\
& + \text { constant }
\end{aligned}
$$

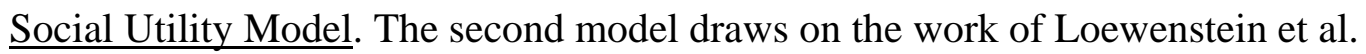
(1989). They find that satisfaction is a function not only of how much money an individual receives, but also of how much money one's counterpart receives. In our framework these are internal comparisons, and we refer to the class of models that use internal comparisons to predict satisfaction as social utility models. Loewenstein et al. (1989) investigate a business negotiation context similar to our negotiation context. In that setting they find that a model that includes both linear and quadratic terms for one's own outcome and for one's partner's outcome offers the best fit for predicting satisfaction.

In the Loewenstein et al. (1989) studies, participants were told how much they and their hypothetical partners received beyond their respective reservation prices. In the present study, participants actually negotiated with a partner and were not told their partner's reservation price. This mimics many actual negotiations where negotiators are never told their partner's reservation price. As a result, participants in this study cannot directly compute their counterpart's surplus. Instead, we asked participants to estimate their counterpart's reservation price, and subtracted this value from the final price to compute perceived partner’s surplus. Our social utility model is depicted in Equation 2.

$$
\begin{gathered}
\text { Satisfaction } \left._{S U}=\beta_{1} \text { (objective outcome }\right)+\beta_{2}{\text { (objective outcome })^{2}} \\
+\beta_{3}{\text { (perceived partner's surplus })+\beta_{4}(\text { perceived partner's surplus })^{2}}^{+ \text {constant }}
\end{gathered}
$$


Expectancy Disconfirmation Model. We borrow the expectancy disconfirmation model from research conducted by Oliver et al. (1994). They find that satisfaction with negotiated outcomes is a function of an individual's profit and of the difference between one's actual outcome and one's expected outcome. In the present study, each participant was asked to predict the most likely outcome of the negotiation before the bargaining session began. We use the difference between this prediction and the actual outcome to measure expectancy disconfirmation (see equation 3).

$$
\begin{aligned}
& \text { Satisfaction }_{E D}=\beta_{1} \text { (objective outcome) } \\
& +\beta_{2} \text { (expectancy disconfirmation) } \\
& + \text { constant }
\end{aligned}
$$

External Social Comparison Model. We measure external social comparison with a question asking participants how well they think their outcome compares to the outcomes of others in their same role. This measure is the only predictor used in the external social comparison model. This model is represented in Equation 4.

$$
\begin{aligned}
\text { Satisfaction }_{S C}= & \beta_{1} \text { (social comparison) } \\
& + \text { constant }
\end{aligned}
$$

Combined Model. This model, depicted in Equation 5, includes all predictors from the four models above. It provides a benchmark to evaluate the performance of our four models.

$$
\begin{gathered}
\text { Satisfaction } \left.=\beta_{1} \text { (objective outcome }\right)+\beta_{2}{\text { (objective outcome })^{2}}^{2} \\
\left.+\beta_{3}(\text { partner's surplus })+\beta_{4} \text { (partner's surplus }\right)^{2} \\
+\beta_{5}(\text { expectancy disconfirmation }) \\
+\beta_{6}(\text { social comparison }) \\
+ \text { constant }
\end{gathered}
$$


We fit each model separately for buyers and sellers, and report the results in Table 1. As expected, several models explain statistically significant amounts of variance in satisfaction, and we describe results from each of these models in turn. The first model in Table 1 is the objective utility model. Consistent with increasing utility and declining marginal utility, for both buyers and sellers the parameter estimates for objective outcome were positive, and the parameter estimates for the quadratic term were negative. The utility parameters, however, were not significant for either buyers or sellers ${ }^{2}$, and overall, the objective utility model was significant for sellers, but not for buyers. The variance accounted for by the objective utility model was significantly less than the combined model $(\underline{F}(4,63)=5.34, \underline{p}<.001$ for buyers; $\underline{F}(4,67)=3.64, \underline{p}<.01$ for sellers).

The second model in Table 1 is the social utility model. As expected, the parameter estimates for partner's outcome were negative for both buyers and sellers. The higher a counterpart's perceived surplus, the less satisfied participants were. This result was statistically significant for sellers, but not buyers. For sellers, we also found diminishing marginal disutility for larger partner outcomes. Overall, the social utility model accounted for a statistically significant portion of satisfaction variance for sellers, but not buyers. The social utility model for sellers captured marginally less variance than the combined model $(\underline{\mathrm{F}}(2,67)=3.05, \mathrm{p}=.054)$. The social utility model for buyers captured significantly less variance than the combined model $(\underline{F}(2,63)=8.35, \underline{p}<.001)$.

The third model shown in Table 1 is the expectancy disconfirmation model. This model identifies a positive relationship between expectancy disconfirmation and

\footnotetext{
${ }^{2}$ For sellers' satisfaction, the linear term becomes significant if the quadratic term is removed, suggesting that there is some reliable linear effect of objective outcome.
} 
satisfaction. The more participants’ outcomes exceeded their expectations, the more satisfied they were. This relationship was significant for buyers, but not for sellers. The expectancy disconfirmation model for both buyers and sellers accounted for significantly less variance than the combined model $(\underline{F}(4,63)=3.60, \underline{p}<.05$ for buyers; $\underline{F}(4,67)=$ 3.64, $\mathrm{p}<.01$ for sellers).

For both buyers and sellers the external social comparison parameters were in the predicted direction and statistically significant. Both groups were more satisfied the better they thought their outcome compared to the outcomes of others in their same role. In addition, these models explained a high proportion of variance in satisfaction. In fact, the variance captured by the social comparison model was not significantly different from the variance captured by the combined model for buyers $(\underline{F}(5,63)<1)$ or sellers $(\underline{F}(5,67)=$ 1.35, ns).

Looking at the coefficient estimates for the combined model, we see that the external social comparison variables remain highly significant predictors of satisfaction controlling for factors identified in previous research. In fact, this is the only parameter that is statistically significant for both buyers and sellers in the combined model.

\section{$\underline{\text { Discussion }}$}

Results from this study suggest that external social comparison is a key determinant of negotiator satisfaction. In fact, in this study once external social comparison values were included in the model, other factors, such as expectations, social utility, and even the agreed price, accounted for very little of the variance in satisfaction. Both buyers and sellers were more satisfied when they thought that others in their position had received less than they had. It is important to note that in this study 
participants were not provided with information about how well others had actually performed. As a result, participants in this study constructed social comparisons in the absence of any immediately available comparison information (e.g. Suls, Marco, and Tobin 1991; Wood, Taylor, and Lichtman 1985), so our findings may offer a conservative test of the importance of external social comparison. If participants had received information about others' outcomes, the social comparison model may have accounted for an even larger proportion of the variance.

Our results also provide some support for the social utility (Loewenstein et al. 1989) and expectancy disconfirmation (Oliver et al. 1994) accounts of satisfaction. Consistent with the social utility prediction, sellers were more satisfied when they perceived that their counterpart earned less surplus. Supporting the expectancy disconfirmation account, we found that buyers were more satisfied when the final price they actually agreed to was low compared to the price they expected to pay ex-ante. For both buyers and sellers, however, social comparison judgments were the most reliable predictor of satisfaction.

Surprisingly, the objective outcome model captured little variance, particularly for buyers. That is, buyers' and sellers' satisfaction did not vary much with changes in the agreed price. Although economic theory suggests that objective prices should dominate uninformed social comparisons, we find the reverse pattern of effects. Our results may be better understood by considering the notion of evaluability introduced by Hsee (1996). Some information (e.g. prices) can be difficult to evaluate in some contexts and easy to evaluate in other contexts. In this experiment, price information may have been difficult 
to evaluate. In Study 5, we examine social comparison effects while manipulating the evaluability of the negotiated price.

\section{Study 3}

In study three we extend our investigation to examine the mechanics of external social comparisons. In this study we manipulate both internal and external social comparison values, and we measure the individual and joint effects of internal and external social comparison cues. This aspect of our design enables us to test the hypothesis that downward external social comparison values increase negotiator satisfaction more than downward internal social comparison values.

In this study we also examine the absolute effect of social comparison cues by comparing to a condition with no social comparison information. This aspect of our design is different from prior work (e.g., Loewenstein et al., 1989), and results from this study can inform the basic decision of whether or not to reveal social comparison information.

$\underline{\text { Method }}$

A total of 265 respondents from a large Northeast train station read and answered questions about a scenario that described the purchase of a rare coin. Each respondent read one of nine versions from a 3 (external social comparison: high, low or none) x 3 (internal social comparison: high, low, or none) factorial design. Across all versions, participants were informed that they purchased the coin for $\$ 80$ and that they would have paid any amount up to $\$ 110$. That is, across all versions participants earned a surplus of \$30. We manipulated external social comparisons by mentioning a friend who had either paid more or less than they had for a similar coin. The friend's surplus was either $\$ 10$, 
\$50 or unspecified. We manipulated internal social comparisons by providing information about the lowest price for which the seller would have been willing to sell the coin. Across conditions, the seller's surplus was either $\$ 10, \$ 50$, or unspecified.

Each respondent saw only one version of the scenario, shown below. Imagine that after traveling with a good friend last summer, you both developed an interest in old coins. You purchased a couple of old coins during your trip, and you are interested in expanding your small collection.

One day, you happen to walk by a local antique show. While looking through a few items, you come across a table with old coins. The seller recently inherited the coins, and he is hoping to make some money. One of the coins catches your eye. It is an old American coin in excellent condition. You decide to purchase the coin if you can get it for any amount below $\mathbf{\$ 1 1 0}$. You start to bargain with the seller, and after a few minutes you agree to pay $\$ \mathbf{8 0}$. [You find out after you make your purchase that the seller would have sold the coin for any amount over $\mathbf{\$ 7 0 / \$ 3 0 . ]}$

As you continue walking through the antique show you happen to run into your friend. You begin to tell your friend about your recent purchase, and it turns out he had also just bought an old coin, from a different seller. You compare the two coins and find that they are very similar. In fact, both coins have the same design, are the same age and both are in excellent condition. [Your friend paid $\mathbf{\$ 1 0 0 / \$ 6 0}$ for his coin.]

After reading the scenario, respondents were asked how satisfied they would be with their purchase on a 9-point scale ranging from "not at all satisfied" to "extremely satisfied.” They were then asked to estimate the value (in dollars) of the coin.

$\underline{\text { Results }}$ 
In an ANOVA model predicting satisfaction, we found significant main effects for both internal $(\mathrm{F}(2,256)=30.7, \mathrm{p}<.001)$ and external social comparison values $(\mathrm{F}(2$, $256)=21.0, \mathrm{p}<.001)$, and a significant interaction $(\mathrm{F}(4,256)=4.89, \mathrm{p}<.001)$. As depicted in Table 2, internal and external social comparisons had very different effects on satisfaction. For internal social comparisons, both upward and downward internal social comparisons decreased satisfaction ( $\mathrm{Ms}=3.10$ and 4.73 , respectively) relative to no internal social comparison information $(M=5.68, t(56)=4.88, p<.001, t(56)=1.77$, $\mathrm{p}=.083)$. For external comparisons, however, the pattern is very different. Upward external comparisons reduced satisfaction (4.41 versus 5.68, t $(55)=2.40, \mathrm{p}<.05$ ), but downward external comparison information markedly increased satisfaction (7.31 versus 5.68, $\mathrm{t}(55)=3.23, \mathrm{p}<.005)$. Upward comparisons with an external referent produced significantly higher satisfaction than upward comparisons with an internal referent ( 7.31 versus 4.73, $\mathrm{t}(57)=5.63, \mathrm{p}<.001)$.

We also find an interesting interaction between internal and external social comparisons. External social comparisons influenced satisfaction more when the internal social comparison was downward (6.63 vs. 4.17) than when the internal social comparison was upward (3.83 vs. 3.80). Similarly, internal social comparisons influenced satisfaction more when the external social comparison was downward (6.63 vs. 3.83) than when the external social comparison was upward (4.73 vs. 3.80). It seems that one unfavorable comparison dampens the effect of any other comparison.

Importantly, we find different effects for downward internal and external social comparisons. Downward external comparisons increased satisfaction, while downward internal comparisons decreased satisfaction. One possible explanation for this asymmetric 
effect is that internal and external social comparisons influence perceptions of value differently. After all, by construction, the lowest price at which the seller would sell is lower than the price the buyer paid, while the price a friend paid could be higher or lower than the price paid by the buyer.

To test whether the social comparison effects we observe in this study influence satisfaction by simply changing perceptions of value, we added perceived value as a covariate in our ANOVA. In this model we find that perceived value is a significant predictor of satisfaction $(\mathrm{F}(2,255)=111, \mathrm{p}<.001)$, but the main effects and interaction of social comparisons remain significant (Fs $>5$, ps $<.005$ ). To test for the effects of social comparison beyond influencing perceptions of value, we ran a regression predicting satisfaction from perceived value and four dummy variables corresponding to the effects of upward and downward internal and external social comparisons. We find that the same social comparison effects remain significant after controlling for perceived value: upward and downward internal comparisons lower satisfaction, upward external comparisons lower satisfaction, and downward external comparisons raise satisfaction.

\section{$\underline{\text { Discussion }}$}

In this study, we manipulated both types of social comparisons, and we find that both significantly influence negotiator satisfaction. When we control for changes in perceptions of value, we still find significant effects of internal and external social comparisons on satisfaction.

Results from this study also reveal qualitative differences between internal and external social comparisons. The key difference between internal and external social comparison values is in the effect of downward comparison values. Compared to a base- 
line case of no social comparison information, we find that downward external social comparison cues increase satisfaction, while downward internal comparison cues decrease satisfaction.

Before running this study, we were not sure whether negotiators would be more or less satisfied upon learning that they had come close to their participant's reservation price. One might imagine several possible reactions to downward internal comparisons: (1) satisfaction with claiming most of the total surplus (i.e., I am glad I got so close to my partner's reservation price), (2) dissatisfaction with advantageous inequity (i.e., I feel badly that my partner did not earn as much as I did), or (3) dissatisfaction upon learning of forgone opportunities to claim additional surplus (i.e., I wish I had gotten even closer to my partner's reservation price). Results from Study 3 are consistent with the second and third reactions, but are not consistent with the first. In our next study we test whether the second or the third reaction is responsible for dissatisfaction following downward internal social comparisons.

\section{Study 4}

In Study 3 we demonstrate an important asymmetry between the effects of internal and external social comparisons. In this study we explore this asymmetry and investigate two possible mechanisms for this effect. First, we consider the possibility that downward internal social comparisons harm satisfaction because they generate feelings of inequality (Loewenstein et al. 1989). That is, negotiators exposed to downward internal social comparison cues may be dissatisfied because they value equality and dislike unequal outcomes. If this is true, negotiator satisfaction should be greater when a counterpart's surplus is higher and closer to one’s own outcome. 
Alternatively, negotiators may be dissatisfied by downward internal social comparisons because any mention of their partner's surplus raises the prospect that they could have earned even more surplus for themselves. If this is true, then satisfaction should decrease as one’s counterpart's surplus is closer to one’s own outcome. Method

We recruited 155 undergraduate students from a Northeastern university to complete one of six versions of a survey. We modified the materials used in Study 3 to create six versions in a 2 (External social comparison: Downward or No information) x 3 (Internal social comparison: Equal, Small surplus, or No surplus) design. As in Study 3, across all versions participants earned a surplus of \$30. We manipulated external social comparisons by mentioning a friend who had either paid more than they had (\$10 surplus) or by providing no information about the friend's purchase price. We manipulated internal social comparisons by providing information about the price for which the seller would have been willing to sell the coin. Across conditions, the seller's surplus was either \$30 (Equal condition), \$10 (Small surplus), or \$0 (No surplus).

Each respondent saw only one version of the materials. After reading the scenario, respondents were asked to indicate how satisfied they were with the purchase using the same scale as Study 3.

\section{$\underline{\text { Results }}$}

We analyzed satisfaction scores using a 2x3 ANOVA (see Table 3). Both main effects were highly significant (Internal $-\mathrm{F}(2,145)=58.4, \mathrm{p}<.001$; External $-\mathrm{F}(1,145)$ $=41.0, \mathrm{p}<.001)$, and there was no significant interaction $(\mathrm{F}<1)$. The key result in this study is the main effect of internal social comparison on satisfaction. As the inequality 
between the outcomes grew, satisfaction increased. Respondents were most satisfied when their counterpart earned no surplus $(M=6.87)$, significantly less satisfied when their counterpart earned a small surplus $(\$ 10 ; \mathrm{M}=6.08, \mathrm{t}(99)=2.51, \mathrm{p}<.02)$, and even less satisfied when their counterpart earned an equal surplus $(\$ 30 ; M=3.62, t(98)=7.26$, $\mathrm{p}<$.001). Replicating results from Study 3, we find that participants were more satisfied with a downward external comparison $(M=6.38)$ than with no external social comparison information $(\mathrm{M}=4.70)$.

\section{$\underline{\text { Discussion }}$}

Results from this study do not support an equality-based explanation for the relationship between social comparisons and satisfaction. Specifically, we find that participants were more satisfied the greater the gap between their surplus and their partner's surplus. This finding suggests that downward internal social comparisons can harm negotiator satisfaction by highlighting missed opportunities to increase one’s surplus.

More broadly, results from this work highlight conceptual and practical differences between internal and external social comparisons. Unlike external social comparisons, both upward and downward internal social comparisons can decrease negotiator satisfaction.

This work, however, does not address an important question about the practical implications of social comparison information. In our previous studies, participants evaluated outcomes in the absence of objective benchmarks. Social comparison information may influence satisfaction very differently when individuals have objective 
standards with which to evaluate their outcome. We investigate this issue in our next study.

\section{Study 5}

In our previous studies, participants’ outcomes were difficult to evaluate. In these settings, social comparison information may have been particularly influential because participants lacked objective benchmarks. In this study, we manipulate outcome evaluability and we measure changes in the influence of external social comparisons on satisfaction.

In many situations, negotiated outcomes are difficult to evaluate. For example, the range of appropriate prices for a used car or appropriate discounts for last season’s fashions are characterized by large zones of indeterminacy (Rees, 1993). In most cases, objective information (e.g., the book value of a used car or information about prior discounts) can make negotiated outcomes easier to evaluate.

Social comparisons may influence satisfaction, in part, by changing perceptions of value. As a result, we expect social comparison information to influence satisfaction more when the situation has low evaluability than when it has high evaluability. However, results from Study 3 revealed that social comparison affects satisfaction above and beyond its effects on the perceived value of the deal. Consequently, we suspect that even in high evaluability situations, social comparison information will affect satisfaction. In this study, we explore this proposition.

$\underline{\text { Method }}$

A total of 202 passengers waiting at a Northeast airport were recruited to participate in this study. We used methods similar to those we used in Studies 3 and 4. 
Participants read a scenario about the purchase of a rare coin. Each respondent saw one version from a 2 (External social comparison: high or low) x 3 (Appraisal value: high, low, or none) factorial design. We manipulated external social comparison by mentioning that a friend had either paid more or less for a similar coin. We manipulated appraisal value by mentioning that an expert appraiser had either valued the coin at more than they had paid, valued the coin at less than they had paid, or did not appraise the coin. We appended the following paragraph to the end of the scenario we used in our previous studies:

Many antique shows sponsor appraisal tables. At this antique show the appraisal table includes professional appraisers, and one of them is an expert in antique coins. You decide to have your coin appraised by the coin specialist. [After a careful inspection, the appraiser tells you that your coin is probably worth $\mathbf{\$ 1 2 0 . 0 R}$ After a careful inspection, the appraiser tells you that your coin is probably worth $\mathbf{\$ 4 5}$. OR The line for the coin appraiser, however, was quite long so you decided not to wait for an appraisal.]

After reading the scenario, respondents were asked how satisfied they would be with their purchase using the same scale as the previous two studies.

\section{$\underline{\text { Results }}$}

We analyzed satisfaction scores using a 2x3 ANOVA with social comparison and appraisal as independent factors. Both main effects were significant $(\underline{F}(1,195)=43.3$, $\underline{p}$ $<.001$ for external social comparison, $\underline{\mathrm{F}}(2,195)=84.1, \mathrm{p}<.001$ for appraisal).

Respondents who were informed that their friend paid less were less satisfied $(\mu=3.92)$ than those who were informed that their friend paid more $(\mu=5.48)$. Respondents in the high appraisal condition were more satisfied $(\mu=6.62)$ than those in the no appraisal 
condition $(\mu=4.67)$, and those in the no appraisal condition were more satisfied than those in the low appraisal condition $(\mu=2.88)$. Supporting our thesis, these main effects were qualified by a significant interaction $(\underline{\mathrm{F}}(2,195)=7.40, \underline{\mathrm{p}}<.001)$. As depicted in Figure 3, social comparison information had the largest effect on satisfaction when no appraisal was given $(\mu=3.31$ versus $\mu=5.94, \underline{\mathrm{t}}(64)=7.00, \underline{\mathrm{p}}<.001)$. This effect was significantly larger than the effect with a low appraisal $(\underline{F}(1,130)=13.2, \underline{p}<.001)$ and significantly larger than the effect with a high appraisal $(\underline{\mathrm{F}}(1,129)=3.90, \underline{\mathrm{p}}<.05)$.

The high appraisal condition showed a greater effect of social comparison information than the low appraisal condition $(\underline{\mathrm{F}}(1,131)=4.01, \underline{\mathrm{p}}<.05)$. Importantly, the effect of social comparison in the high appraisal condition was significant $(\mu=5.80$ versus $\mu=7.41$, $\underline{\mathrm{t}}(65)=4.53, \underline{\mathrm{p}}<.001$ ), while in the low appraisal condition there was no significant effect of social comparison information $(\mu=2.68$ versus $\mu=3.09$, $\underline{\mathrm{t}}<1)$.

\section{$\underline{\text { Discussion }}$}

As predicted, the influence of external social comparison information was greater when there was no appraisal than when there was an appraisal. This result supports the proposition that the evaluability of an outcome moderates the influence of social comparison information on satisfaction. However, we still find that social comparison information matters when objective information is evaluable and positive. In this case, social comparison information influenced satisfaction despite the presence of objective information.

We also found that social comparison information did not significantly influence satisfaction when objective information was evaluable and negative. This result suggests that social comparison information may depress satisfaction with a deal that is known to 
be good more easily than it can increase satisfaction with a deal that is known to be bad. This asymmetry parallels the asymmetry found in Study 3, whereby adding information to a situation where there is already a negative impression of the negotiated outcome had little effect, while adding the same information when there is a positive impression has a substantial effect.

\section{General Discussion}

In this paper we examine the influence of social comparisons on negotiator satisfaction. We make a conceptual distinction between internal social comparisons, comparisons made with a negotiation counterpart (e.g., a buyer comparing his surplus to the seller's surplus), and external social comparisons, comparisons with negotiators in similar situations outside of one’s own negotiation (e.g., a car buyer comparing his surplus to the surplus of another buyer purchasing a similar car). Across five studies we demonstrate that the effects of internal and external social comparisons on satisfaction are qualitatively different. In particular, while downward external social comparisons increase negotiator satisfaction, similar downward internal social comparisons decrease negotiator satisfaction. This may happen because even downward internal social comparison values focus negotiator's attention on missed opportunities to claim additional surplus.

Our distinction between internal and external social comparisons also has practical implications. First, the set of available external comparison values is typically very different from the set of available internal comparison values. For example, a car salesperson who has just concluded a negotiation with a buyer has a relatively constrained set of internal social comparisons from which to choose. The seller could 
either conceal or reveal her surplus (or possibly misrepresent her surplus). With respect to external social comparisons, however, the seller has the option of selecting from a number of prior negotiation outcomes. In this case, the seller has a much broader set of external social comparison alternatives than internal social comparison alternatives, and her ability to identify a credible downward external social comparison is greater than her ability to identify a downward internal social comparison.

Internal and external social comparisons are also very different with respect to the type of information they convey. Specifically, unlike external social comparison values, internal social comparison values convey information that is explicit about missed opportunities to claim additional surplus. Consistent with our findings, this difference suggests that internal social comparisons will be more likely to lower satisfaction than external social comparisons.

More broadly, results from our work demonstrate that satisfaction judgments are very labile and subject to manipulation. Both internal social comparisons and external social comparisons are key drivers of satisfaction, and prescriptively, negotiators should recognize that the satisfaction their counterparts derive from a negotiation may have less to do with the actual concessions they make (e.g. objective profit) than the comparison information they provide. In our studies we find that the effects of social comparisons on satisfaction are not mediated by value. That is, negotiators have preferences for outperforming others that are separate from their preference for the value of the outcome itself.

A number of factors are likely to moderate the importance of social comparisons on satisfaction. For example, in Study 5 we found that evaluability moderates the 
influence of social comparison information on satisfaction. Social comparison information matters most in cases where outcomes are difficult to evaluate or objective information is favorable. Future research should explore the effects of evaluability on satisfaction more broadly, and consider a number of other individual and contextual factors that are likely to moderate the influence of social comparison information on negotiator satisfaction. For example, future work could consider the importance of a negotiator's relationship with his or her partner, a negotiator's level of experience with the particular negotiation situation, a negotiator's emotional state, and the interplay between social comparison information and other aspects of the negotiation process (e.g., Schweitzer \& Kerr, 2000; Schweitzer \& Gomberg, 2001).

In addition, future research should explore the selection and construction of comparisons. In experimental studies social comparison values are often provided (e.g., De Dreu, Lualhati \& McCusker, 1994; Messick \& Sentis, 1985; Ordonez, Connolly, \& Coughlan, 2000). In many settings, however, social comparison values are generated or selected by the negotiator. In some cases, individuals may select from multiple social comparison values or even generate social comparison judgments in the absence of comparison information. For example, people may develop a sense of how others would perform and construct a social comparison judgment grounded in assumptions about their own negotiation skill relative to others. Perhaps, in the absence of social comparison information people tend to generate favorable social comparisons. In our studies we included conditions of no information, and we find that in many cases negotiators were more satisfied with no information than they were with the social comparison information we provided. In particular, our results suggest that negotiators are often disappointed to 
learn about a counterpart's surplus, even when their counterpart's surplus is far smaller than their own. It is important to note that our studies focused on the effects of social comparison, once that information is made available. While our data provide some insight into the effects on satisfaction of introducing social comparison information, these results largely ignore the question of when and how people seek out this information. Clearly, more research is needed to understand how social comparison judgments are constructed in natural negotiation contexts.

Although the vast majority of negotiation studies focus on the negotiation process itself (see Bazerman, Curhan, Moore, \& Valley, 2000), post-negotiation behaviors (e.g., offers to make amends; Gibson, Bottom, \& Murnighan, 1999) can have profound effects on how negotiation counterparts interact with each other following a negotiation. For example, post-negotiation actions may significantly influence a negotiators’ preferences for repeated interactions, commitment to a deal, and willingness to cooperate in domains not explicitly covered in an agreement (e.g., how hard an employee works following contract negotiations). Revealing comparison information can be conceptualized as another post negotiation behavior that individuals can use to influence their counterpart's future behavior. Additional work remains to develop our understanding of how social comparisons influence both proximal and distant negotiator behavior. 


\section{References}

Barry, B., \& Oliver, R. (1996). Affect in dyadic negotiation: A model and propositions, Organizational Behavior and Human Decision Processes, 67, 127-143.

Bazerman, M., Curhan, J., Moore, D. \& Valley, K. (2000). Negotiation, Annual Review of Psychology, 51, 279-314.

Blount, S., Thomas-Hunt, M., \& Neale, M. (1996). The price is right - or is it? A reference point model of two-party price negotiations, Organizational Behavior and Human Decision Processes, 68, 1-12.

Brett, J., Northcraft, G., \& Pinkley, R. (1999). Stairways to heaven: An interlocking selfregulation model of negotiation, The Academy of Management Review, 24, 435-451.

Conlon, D. \& Ross, W. (1993). The effects of partisanship on negotiator behavior and outcome perceptions, Journal of Applied Psychology, 78, 280-290.

De Dreu, C., Lualhati, J., \& McCusker, C. (1994). Effects of gain and loss frames on satisfaction with self and other outcome differences, European Journal of Social Psychology, 24, 497-510.

Festinger, L. (1954). A Theory of Social Comparison Processes, Human Relations, 7, $117-140$. 
Galinsky, A., Seiden, V., Kim, P., \& Medvec, V. (2002) The dissatisfaction of having your first offer accepted: The role of counterfactual thinking in negotiations, Personality and Social Psychology Bulletin, 28, 271-283.

Gibson, K., Bottom, W., Murnighan, J. (1999). Once bitten: Defection and reconciliation in a cooperative enterprise. Business Ethics Quarterly, 9, 69-85.

Gillespie, J., Brett, J. \& Weingart, L. (2000). Interdependence, social motives, and outcome satisfaction in multiparty negotiation, European Journal of Social Psychology, 30, 779-797.

Goethals, A. \& Darley, J. (1977). in Social Comparison Processes: Theoretical and Empirical Perspectives Eds. J. Suls and R. Miller, Washington D.C.: Hemisphere.

Hsee, C. (1996). The evaluability hypothesis: An explanation for preference reversals between joint and separate evaluations of alternatives, Organizational Behavior \& Human Decision Processes, 67, 247-257.

Larrick, R. and Wu, G. (2003). Claiming a large slice of a small pie: Asymmetric Disconfirmation in Negotiation. Unpublished manuscript, University of Chicago. 
Loewenstein, G., Thompson, L., \& Bazerman, M. (1989). Social Utility and Decision Making in Intertemporal Contexts, Journal of Personality and Social Psychology, 57, 426-441.

Messick, D. \& Sentis, K. (1985). Estimating social and nonsocial utility functions from ordinal data, European Journal of Social Psychology, 15, 389-399.

Moran, S. \& Ritov, I. (2002). Initial perceptions in negotiation: Evaluation and response to ‘logrolling’ offers, Journal of Behavioral Decision Making, 15, 101-124.

Naquin, C. (2003). The agony of opportunity in negotiation: Number of negotiable issues, counterfactual thinking, and feelings of satisfaction, Organizational Behavior and Human Decision Processes, 91, 97-107.

Oliver, R., Balakrishnan, P., \& Barry, B. (1994). Outcome Satisfaction in Negotiation: A Test of Expectancy Disconfirmation, Organizational Behavior and Human Decision Processes, 60, 252-275.

Ordonez, L, Connolly, T., \& Coughlan, R. (2000). Multiple reference points in satisfaction and fairness assessment, Journal of Behavioral Decision Making, 13, 329344. 
Pinkley, R., Griffith, T., \& Northcraft, G. (1995). 'Fixed pie’ a la mode: Information availability, information processing, and the negotiation of suboptimal agreements, Organizational Behavior and Human Decision Processes, 62, 101-112.

Rees, A. 1993. The role of fairness in wage determination. Journal of Labor Economics, $11,243-52$.

Schweitzer, M. \& Gomberg, L. (2001). The impact of alcohol on negotiator behavior: Experimental evidence. Journal of Applied Social Psychology, 31, 2095-2126.

Schweitzer, M., \& Kerr, J. (2000). Bargaining under the influence: The role of alcohol in negotiations. Academy of Management Executive, 14, 47-57.

Suls, J., Marco, C. \& Tobin, S. (1991). “The role of temporal comparison, social comparison, and direct appraisal in the elderly's self-evaluations of health,” Journal of Applied Social Psychology, 21, 1125-1144.

White, S. \& Neale, M. (1994). The role of negotiator aspirations and settlement expectancies in bargaining outcomes. Organizational Behavior and Human Decision Processes, 57, 303-317.

Wood, J., Taylor, S., \& Lichtman, R. (1985). "Social comparison in adjustment to breast cancer,” Journal of Personality and Social Psychology, 49, 1169-1183. 
Table 1: Models of Satisfaction (Study 2)

\begin{tabular}{|c|c|c|c|c|c|c|c|}
\hline \multirow[t]{2}{*}{ Model Type } & \multirow[t]{2}{*}{ Model Fit } & \multicolumn{6}{|c|}{$\begin{array}{l}\text { Beta Weights } \\
\text { (Standard Error) }\end{array}$} \\
\hline & & $\begin{array}{l}\text { Objective } \\
\text { Outcome }\end{array}$ & \begin{tabular}{|l|} 
(Objective \\
Outcome)
\end{tabular} & \begin{tabular}{|l|} 
Partner's \\
Outcome
\end{tabular} & $\begin{array}{l}\text { (Partner's } \\
\text { Outcome) }\end{array}$ & \begin{tabular}{|l||} 
Expectancy \\
Disconfirmation
\end{tabular} & $\begin{array}{l}\text { Social } \\
\text { Comparison }\end{array}$ \\
\hline \multicolumn{8}{|c|}{ Buyers' Models } \\
\hline $\begin{array}{l}\text { Economic } \\
\text { Utility Model }\end{array}$ & $\begin{array}{l}\text { Adj. } \mathrm{R}^{2}=.007 \\
\mathrm{~F}(2,67)=1.24\end{array}$ & $\begin{array}{l}.349 \\
(.330)\end{array}$ & $\begin{array}{l}-.185 \\
(.330)\end{array}$ & & & & \\
\hline $\begin{array}{l}\text { Social Utility } \\
\text { Model }\end{array}$ & $\begin{array}{l}\text { Adj. } R^{2}=.033 \\
F(4,65)=1.59\end{array}$ & $\begin{array}{l}.370 \\
(.331)\end{array}$ & $\begin{array}{l}-.177 \\
(.330)\end{array}$ & $\begin{array}{l}-.108 \\
(.357)\end{array}$ & \begin{tabular}{|l|}
-.129 \\
$(.353)$
\end{tabular} & & \\
\hline $\begin{array}{l}\text { Expectancy } \\
\text { Disconfirmation } \\
\text { Model }\end{array}$ & $\begin{array}{l}\text { Adj. } R^{2}=.089^{*} \\
F(2,67)=4.38^{*}\end{array}$ & $\begin{array}{l}.111 \\
(.118)\end{array}$ & & & & $\begin{array}{l}.298^{*} \\
(.118)\end{array}$ & \\
\hline $\begin{array}{l}\text { Social } \\
\text { Comparison } \\
\text { Model }\end{array}$ & \begin{tabular}{|l|} 
Adj._R $\mathrm{R}^{2}=.228^{* * *}$ \\
$\mathrm{~F}(1,68)=21.38^{* * *}$
\end{tabular} & & & & & & $\begin{array}{l}.489 * * * \\
(.106)\end{array}$ \\
\hline $\begin{array}{l}\text { Combined } \\
\text { Model }\end{array}$ & $\begin{array}{l}\text { Adj. } \mathrm{R}^{2}=.211^{* *} \\
\mathrm{~F}(6,63)=4.08^{* *}\end{array}$ & $\begin{array}{l}.076 \\
(.314)\end{array}$ & $\begin{array}{l}-.109 \\
(.302) \\
\end{array}$ & \begin{tabular}{|l}
-.030 \\
$(.327)$
\end{tabular} & $\begin{array}{l}-.086 \\
(.321)\end{array}$ & $\begin{array}{l}.191 \\
(.117)\end{array}$ & $\begin{array}{l}.401 * * \\
(.134)\end{array}$ \\
\hline \multicolumn{8}{|l|}{ Sellers’ Models } \\
\hline $\begin{array}{l}\text { Economic } \\
\text { Utility Model }\end{array}$ & $\begin{array}{l}\text { Adj. } \mathrm{R}^{2}=.064 * \\
\mathrm{~F}(2,71)=3.49^{*}\end{array}$ & $\begin{array}{l}.361 \\
(.473)\end{array}$ & $\begin{array}{l}-. .064 \\
(.473)\end{array}$ & & & & \\
\hline $\begin{array}{l}\text { Social Utility } \\
\text { Model }\end{array}$ & $\begin{array}{l}\text { Adj. } \mathrm{R}^{2}=.136^{* *} \\
\mathrm{~F}(4,69)=3.88^{* *}\end{array}$ & $\begin{array}{l}.380 \\
(.460) \\
\end{array}$ & $\begin{array}{l}-.140 \\
(.462) \\
\end{array}$ & \begin{tabular}{|l}
$-.734 * *$ \\
$(.264)$ \\
\end{tabular} & $\begin{array}{l}.613^{*} \\
(.257) \\
\end{array}$ & & \\
\hline \begin{tabular}{|l|} 
Expectancy \\
Disconfirmation \\
Model
\end{tabular} & $\begin{array}{l}\text { Adj. } R^{2}=.064^{*} \\
F(2,71)=3.49^{*}\end{array}$ & $\begin{array}{l}.297^{*} \\
(.114)\end{array}$ & & & & $\begin{array}{l}.015 \\
(.114)\end{array}$ & \\
\hline $\begin{array}{l}\text { Social } \\
\text { Comparison } \\
\text { Model }\end{array}$ & \begin{tabular}{|l|} 
Adj. $\mathrm{R}^{2}=.165^{* * *}$ \\
$\mathrm{~F}(1,72)=15.44^{* * *}$
\end{tabular} & & & & & & $\begin{array}{l}.420 * * * \\
(.107)\end{array}$ \\
\hline $\begin{array}{l}\text { Combined } \\
\text { Model }\end{array}$ & $\begin{array}{l}\text { Adj. } \mathrm{R}^{2}=.185^{* *} \\
\mathrm{~F}(6,67)=3.76^{* *}\end{array}$ & $\begin{array}{l}.152 \\
(.459)\end{array}$ & $\begin{array}{l}-.003 \\
(.451) \\
\end{array}$ & $\begin{array}{l}-.564^{*} \\
(.266)\end{array}$ & $\begin{array}{l}.516 \\
(.257) \\
\end{array}$ & $\begin{array}{l}-.006 \\
(.108)\end{array}$ & $\begin{array}{l}.298^{*} \\
(.122) \\
\end{array}$ \\
\hline $\begin{array}{ll}* & \mathrm{p}<.05 \\
* * & \mathrm{p}<.01 \\
* * * & \mathrm{p}<.001\end{array}$ & & & & & & & \\
\hline
\end{tabular}


Table 2: Mean Satisfaction Judgments (Study 3)

\begin{tabular}{|c|c|c|c|}
\hline \multirow{2}{*}{ External Social } & \multicolumn{3}{|c|}{ Internal Social Comparison } \\
\cline { 2 - 4 } Comparison & Downward & No Information & Upward \\
\hline \multirow{2}{*}{ Downward } & 6.63 & 7.31 & 3.83 \\
(Smaller Surplus) & $\mathrm{SD}=1.65$ & $\mathrm{SD}=1.61$ & $\mathrm{SD}=1.97$ \\
& $\mathrm{~N}=30$ & $\mathrm{~N}=29$ & $\mathrm{~N}=29$ \\
\hline & 4.73 & 5.68 & 3.10 \\
No Information & $\mathrm{SD}=1.89$ & $\mathrm{SD}=2.18$ & $\mathrm{SD}=1.85$ \\
& $\mathrm{~N}=30$ & $\mathrm{~N}=28$ & $\mathrm{~N}=30$ \\
\hline Upward & 4.17 & 4.41 & 3.80 \\
(Greater Surplus) & $\mathrm{SD}=1.97$ & $\mathrm{SD}=1.78$ & $\mathrm{SD}=2.46$ \\
& $\mathrm{~N}=30$ & $\mathrm{~N}=29$ & $\mathrm{~N}=30$ \\
\hline
\end{tabular}

Satisfaction Rating (1: Not at all satisfied, 9: Extremely satisfied) 
Table 3: Mean Satisfaction Judgments (Study 4)

\begin{tabular}{|c|c|c|c|}
\hline \multirow{2}{*}{ External Social } & \multicolumn{3}{|c|}{ Internal Social Comparison } \\
\cline { 2 - 4 } Comparison & Equal Surplus & Smaller Surplus & No Surplus \\
\hline Downward & 4.54 & 6.80 & 7.67 \\
(Smaller Surplus) & $\mathrm{SD}=1.86$ & $\mathrm{SD}=1.04$ & $\mathrm{SD}=1.65$ \\
& $\mathrm{~N}=24$ & $\mathrm{~N}=25$ & $\mathrm{~N}=26$ \\
\hline \multirow{3}{*}{ No information } & 2.77 & 5.36 & 6.04 \\
& $\mathrm{SD}=1.77$ & $\mathrm{SD}=1.15$ & $\mathrm{SD}=1.62$ \\
& $\mathrm{~N}=26$ & $\mathrm{~N}=25$ & $\mathrm{~N}=25$ \\
\hline
\end{tabular}

Satisfaction Rating (1: Not at all satisfied, 9: Extremely satisfied) 
Figure 1: Social Comparison Judgment by Social Referent (Study 1)

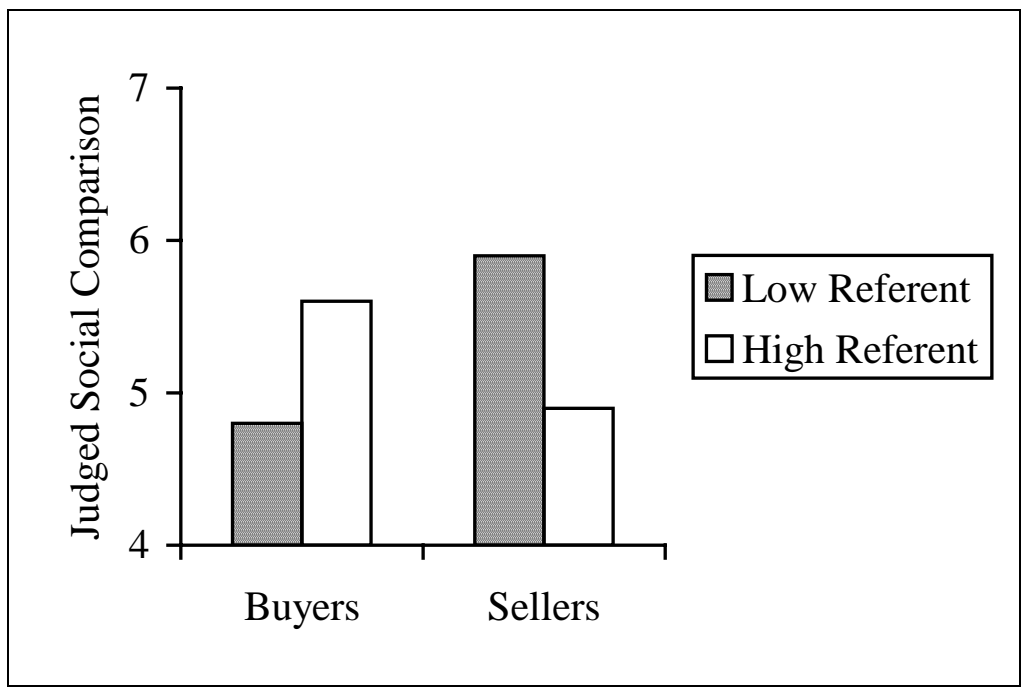


Figure 2: Satisfaction Judgment by Social Referent (Study 1)

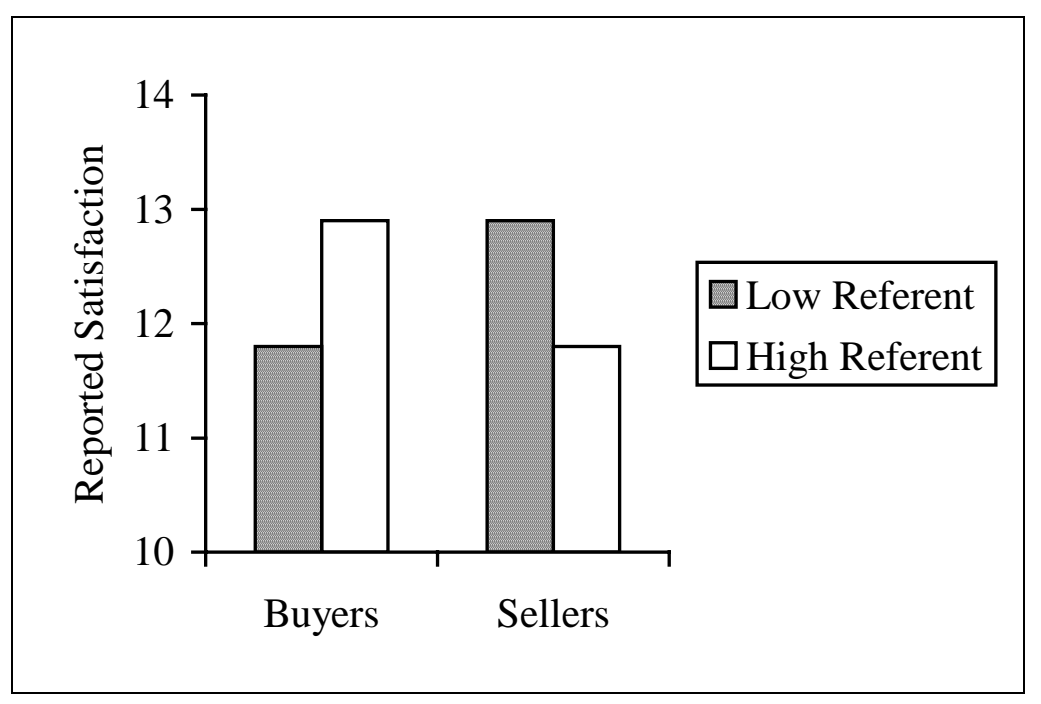


Figure 3: Satisfaction Judgments (Study 5)

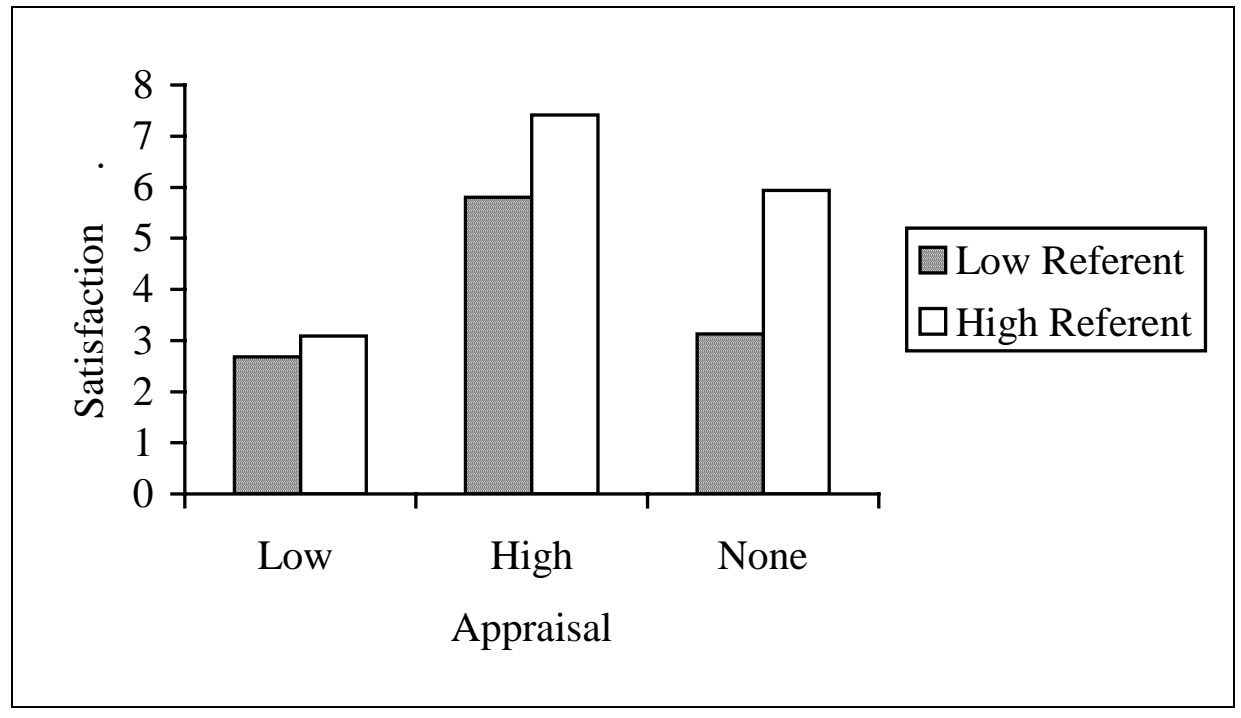

